\title{
Effect of Alpinia zerumbet components on antioxidant and skin diseases-related enzymes
}

\author{
Jamnian Chompoo ${ }^{1}$, Atul Upadhyay ${ }^{1}$, Masakazu Fukuta ${ }^{2}$ and Shinkichi Tawata ${ }^{2 *}$
}

\begin{abstract}
Background: The skin is chronically exposed to endogenous and environmental pro-oxidant agents, leading to the harmful generation of reactive oxygen species. Antioxidant is vital substances which possess the ability to protect the body from damage cause by free radicals induce oxidative stress. Alpinia zerumbet, a traditionally important economic plant in Okinawa, contains several interesting bioactive constituents and possesses health promoting properties. In this regard, we carried out to test the inhibitory effect of crude extracts and isolated compounds from A. zerumbet on antioxidant and skin diseases-related enzymes.

Methods: The antioxidant activities were examined by DPPH, ABTS and PMS-NADH radical scavenging. Collagenase, elastase, hyaluronidase and tyrosinase were designed for enzymatic activities to investigate the inhibitory properties of test samples using a continuous spectrophotometric assay. The inhibitory capacity of test samples was presented at half maximal inhibitory concentration $\left(I C_{50}\right)$.

Results: The results showed that aqueous extract of the rhizome was found to have greater inhibitory effects than the others on both of antioxidant and skin diseases-related enzymes. Furthermore, 5,6-dehydrokawain (DK), dihydro-5,6-dehydrokawain (DDK) and 8(17),12-labdadiene-15,16-dial (labdadiene), isolated from rhizome, were tested for antioxidant and enzyme inhibitions. We found that DK showed higher inhibitory activities on DPPH, ABTS and PMS-NADH scavenging $\left(I C_{50}=122.14 \pm 1.40,110.08 \pm 3.34\right.$ and $127.78 \pm 4.75 \mu \mathrm{g} / \mathrm{ml}$, respectively). It also had stronger inhibitory activities against collagenase, elastase, hyaluronidase and tyrosinase $\left({ }^{2} C_{50}=24.93 \pm 0.97\right.$, $19.41 \pm 0.61,19.48 \pm 0.24$ and $76.67 \pm 0.50 \mu \mathrm{g} / \mathrm{ml}$, respectively) than DDK and labdadiene.
\end{abstract}

Conclusion: Our results indicate that the rhizome aqueous extract proved to be the source of bioactive compounds against enzymes responsible for causing skin diseases. Moreover, DK could be used as a potent inhibitor and be further exploited to be used in anti-skin disease formulations.

Keywords: Alpinia zerumbet, Antioxidant, Skin diseases-related enzymes, 5,6-Dehydrokawain (DK)

\section{Background}

The skin is the largest organ of the human, both in terms of surface area and weight, which serves as an important environmental interface providing a protective envelope that is crucial for homeostasis. On the other hand, the skin is a major target for toxic insult by a broad spectrum of physical (UV radiation) and chemical (xenobiotic) agents that are capable of altering its structure and function [1]. Many environmental pollutants are oxidants or catalyze the production of reactive oxygen species (ROS)

\footnotetext{
* Correspondence: b986097@agr.u-ryukyu.ac.jp

${ }^{2}$ Department of Bioscience and Biotechnology, Faculty of Agriculture, University of the Ryukyus, Senbaru 1, Nishihara-cho, Okinawa 903-0213, Japan

Full list of author information is available at the end of the article
}

directly or indirectly. ROS act as cell-signaling molecules and can react with DNA, proteins, fatty acids and saccharides causing oxidative damages. Such injuries result in a number of harmful effects (disturbed cell metabolism, morphological and ultrastructural changes), attack on the regulation pathways, and alterations in the differentiation, proliferation and apoptosis of skin cells [2]. The skin possesses an array of defense mechanisms that interact with toxicants to obviate their deleterious effects. These include non-enzymatic and enzymatic molecules that function as potent antioxidant or oxidant-degrading systems [3]. For screening antioxidants, the methods based on a single relatively stable reagent such as $\mathrm{DPPH} \cdot$ and $\mathrm{ABTS}^{+}$have most popular, because of their simple set-up and ease of control [4].

\section{() Biomed Central}


Collagenase is one of the few proteinases capable of degrading the triple-helical region of native collagen under a physiological condition. Collagen is the fibrous component of the extracellular matrix (EMC) in the skin and the collagen content in the skin decreases greatly during the aging process and due to long-term exposure to UV radiation. Inhibition of collagenase plays an important role in protecting unbalanced turn over or rapid breakdown of collagen in human inflamed or UVirradiated skin [5]. Elastase is a proteolytic enzyme involved in the degradation of the EMC that includes elastin. Loss of elastin is a major part of what cause visible signs of aging (wrinkles, sagging) in the skin. Elastase secretion and activation caused by exposure to UV light or ROS, an approach that inhibits the elastase activity, could also be applied as a useful method to protect against skin diseases [6]. Hyaluronidase is a mucopolysaccharase that hydrolyzes glycosaminoglycans, including hyaluronic acid, in the EMC during tissue remodeling. When the level of hyaluronic acid decreased under conditions in which the hyaluronidase activity is increased, the moisture and tension of the skin are reduced. Thus, hyaluronidase inhibitors are useful cosmeceutical ingredients as they have anti-wrinkle and anti-aging effects on the skin [7]. Tyrosinase is known to be a key enzyme for the melanin biosynthesis, the compound largely responsible for hair and skin color in mammals. Melanin pigments play a crucial protective role against skin photocarcinogenesis. Tyrosinase inhibitors may be clinically helpful in dealing with skin diseases [8].

Alpinia zerumbet (Family Zingiberaceae) is a medicinal plant found in several islands of Japan, including Okinawa. Several pharmacological effects of essential oil from the leaves of $A$. zerumbet have been used for skin care, insect repellent and deodorant products [9], antinociceptive effects on mice [10] and antihypertensive and cardiovascular effects on rat [11]. We have reported phenolic compounds and their antioxidant activities in leaves and rhizomes of $A$. zerumbet [12] and have isolated active compounds from the rhizomes of $A$. zerumbet against HIV-1 integrase and neuraminidase enzymes [13]. Recently, we have reported the inhibitory effects of this plant on advanced glycation end products formation [14]. Considering all these aspects, the present study was undertaken to evaluate antioxidant and anti-enzymatic activities of $A$. zerumbet for prevention of the skin diseases.

\section{Methods}

\section{Chemicals}

1,1-Diphenyl-2-picrylhydrazyl (DPPH), tert-butyl hydroxytoluene (BHT), kojic acid, gallic acid, 2,2'-azino-bis(3ethylbenzothiazoline-6-sulfonic acid)diammonium salt
(ABTS), nitro blue tetrazolium (NBT), phenazine methosulfate (PMS), bovine serum albumin (BSA) and FolinCiocalteu reagent were purchased from Wako Pure Chemical Industries, Ltd (Japan). Nicotinamide adenine dinucleotide-reduced (NADH), N-succ-(Ala)3-nitroanilide (SANA), N-[3-(2-furyl)acryloyl]-Leu-Gly-Pro-Ala (FALGPA), collagenase, elastase, hyaluronidase, tyrosinase, hyaluronic acid and oleanolic acid were secured from Sigma-Aldrich, Inc. (USA).

\section{Preparation of plant extracts}

The six structures (rhizomes, stems, leaves, flowers, pericarps, and seeds) of $A$. zerumbet were collected at the University of the Ryukyus, Okinawa, Japan. Aqueous extract was obtained by boiling $10 \mathrm{~g}$ of air-dried sample for $20 \mathrm{~min}$. For ethanol extract, samples were immersed in ethanol for $24 \mathrm{~h}$. The aqueous and ethanol extracts were filtered, dried under vacuum and then dissolved in corresponding solvent (water and methanol, respectively) for further analysis.

\section{Isolation and quantification of DK, DDK and labdadiene}

The isolation of DK and DDK were isolated from rhizomes of $A$. zerumbet as reported previously [13]. DK and DDK were purified using a TSK gel ODS-100Z column (15 x $0.46 \mathrm{~cm}$ i.d.; $5 \mu \mathrm{m}$ particle size) (Tosoh Corp, Japan) and monitored continuously at $280 \mathrm{~nm}$. The mobile phase consisted of water with $0.1 \%$ acetic acid (solvent A) and methanol with $0.1 \%$ acetic acid (solvent B) at a flow rate of $0.8 \mathrm{ml} / \mathrm{min}$. The gradient elution was performed as follows: $1-10 \mathrm{~min}, 50 \% \mathrm{~B}$ isocratic, 10$20 \mathrm{~min}$, linear gradient $80-100 \% \mathrm{~B}$, and $20-30 \mathrm{~min}$, $100 \%$ B [14].

Labdadiene was isolated by reported previously [14] and was collected at $235 \mathrm{~nm}$ using TSK gel ODS-100Z column. The mobile phase was water with $0.1 \%$ acetic acid (solvent $\mathrm{A}$ ) and methanol with $0.1 \%$ acetic acid (solvent B) at flow rate of $0.8 \mathrm{ml} / \mathrm{min}$. The gradient elution was performed as follows: $0-10 \mathrm{~min}, 80 \% \mathrm{~B}$ isocratic; $10-20 \mathrm{~min}$, linear gradient $80-100 \% \mathrm{~B}, 20-40 \mathrm{~min}$, $100 \%$ B isocratic.

The quantification of each compound in six different structures of $A$. zerumbet with aqueous and ethanol extracts was determined based on peak area measurement by the same processes as described above. The structures of DK, DDK and labdadiene are shown in Figure 1. The isolated compounds were dissolved methanol for further analysis.

\section{Antioxidant assays \\ DPPH radical scavenging activity assay}

The free radical scavenging activity was evaluated as described previously [15]. Five hundred microlilters of the different concentration of test samples were mixed 


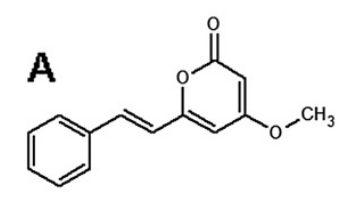<smiles>COc1cc(CCc2ccccc2)oc(=O)c1</smiles>

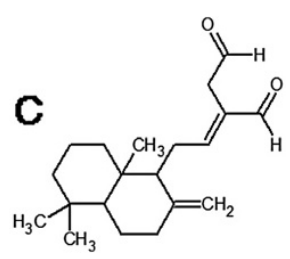

Figure 1 Chemical structures of 5,6-dehydrokawain; DK (A), dihydro-5,6-dehydrokawain; DDK (B) and 8(17),12- labdadiene-15,16-dial; labdadiene (C).

with $200 \mu \mathrm{l}$ of $0.5 \mathrm{mM}$ DPPH methanol solution and $500 \mu \mathrm{l}$ of $0.1 \mathrm{M}$ sodium acetate buffer ( $\mathrm{pH} 5.5)$. After shaking, the mixture was incubated in the dark at room temperature for $30 \mathrm{~min}$, and then the absorbance was measured at $517 \mathrm{~nm}$. BHT was used as a positive control, while water and methanol were used as controls for calculation.

\section{Total antioxidant activity (ABTS) assay}

The total antioxidant activity of test sample was measured with modified method as described previously [16]. ABTS $^{+}$solution was generated by mixing $7 \mathrm{mM}$ ABTS and $2.45 \mathrm{mM}$ potassium persulfate $\left(\mathrm{K}_{2} \mathrm{~S}_{2} \mathrm{O}_{8}\right)$ in water, which was placed in the dark at room temperature for $16 \mathrm{~h}$ to give the complete oxidation of ABTS. Before using, the $\mathrm{ABTS}^{+}$solution was diluted with water to get an absorbance of $0.700 \pm 0.050$ at $734 \mathrm{~nm}$. Briefly, $1 \mathrm{ml}$ of $\mathrm{ABTS}^{+}$solution was added to $30 \mu \mathrm{l}$ of test samples and mixed thoroughly. BHT was used as positive control and the sample solutions were used as controls. The reactive mixture was incubated at room temperature for $6 \mathrm{~min}$ and the absorbance was immediately recorded at $734 \mathrm{~nm}$.

\section{PMS-NADH system superoxide-radical scavenging assay}

The superoxide scavenging activity was assayed following the method of Lau et al. [17] with minor modifications. The reaction mixture contained $0.5 \mathrm{ml}$ of $105 \mu \mathrm{M} \mathrm{NADH}$, $0.5 \mathrm{ml}$ of $66 \mu \mathrm{M}$ NBT dissolved in $0.1 \mathrm{M}$ phosphate buffer (pH 7.4) and $0.1 \mathrm{ml}$ sample in different concentrations. The reaction was initiated by adding $0.5 \mathrm{ml}$ of $30 \mu \mathrm{M}$ PMS into the reaction mixture. Methanol and water were used as a control and BHT as a positive control. After $10 \mathrm{~min}$, the reaction mixture reached to stable color, measurement of absorbance was conducted at $560 \mathrm{~nm}$.

The ability of the extracts to scavenge DPPH, ABTS.+, PMS-NADH radicals were calculated by following formula:

$$
\text { Radical scavenging }(\%)=\left[\left(\mathrm{O}^{\mathrm{D}} \mathrm{D}_{\text {control }}-\mathrm{O} . \mathrm{D}_{\text {sample }}\right) /\right.
$$$$
\text { O.D control }] \times 100 \text {, }
$$

where O.D is the optical density in the presence or absence of the samples.

\section{Determination of total phenolic contents}

The amount of total phenolics was determined using the Folin-Ciocalteu reagent method [18]. Briefly, $0.5 \mathrm{ml}$ of Folin-Ciocalteu reagent and $0.5 \mathrm{ml}$ of distilled water were added to $0.2 \mathrm{ml}$ of each extract dissolved in corresponding solvent $(1 \mathrm{mg} / \mathrm{ml})$. After $1 \mathrm{~min}, 0.8 \mathrm{ml}$ of sodium carbonate solution $(7.5 \%)$ was added in mixture and incubated at room temperature for $30 \mathrm{~min}$. Absorbance was measured at $760 \mathrm{~nm}$. Total phenolic contents were expressed as gallic acid equivalents (GAE) in milligrams per gram extract.

\section{Enzymatic assays}

\section{Collagenase inhibition assay}

Collagenase inhibition assay was performed by the method described previously [19] which based on the hydrolysis of $\mathrm{N}$-[3-(2-furyl)acryloyl]-Leu-Gly-Pro-Ala (FALGPA) by collagenase to produce FA-Leu and Gly-Pro-Ala. The assay was performed in $50 \mathrm{mM}$ Tricine buffer $(400 \mathrm{mM} \mathrm{NaCl}$ and $10 \mathrm{mM} \mathrm{CaCl}_{2}, \mathrm{pH}$ 7.5). Collagenase from Clostridium histolyticum $(\mathrm{ChC})$ was dissolved in the buffer for use at an initial concentration of 0.8 units/ $\mathrm{ml}$. The synthetic substrate, FALGPA, was dissolved in the Tricine buffer to $2 \mathrm{mM}$. Sample extracts were incubated with the enzyme in the buffer for $15 \mathrm{~min}$ before adding substrate to start reaction. The final reaction mixture (150 $\mu \mathrm{l}$ total volume) contained Tricine buffer, $0.8 \mathrm{mM}$ of FALGPA, 0.1 units of ChC and $25 \mu \mathrm{g}$ of test extracts. Controls were performed with water and methanol, while oleanolic acid as a positive control. After adding substrate for $20 \mathrm{~min}$, collagenase activity was measured at $340 \mathrm{~nm}$.

\section{Elastase inhibition assay}

Elastase inhibition was assayed using $\mathrm{N}$-succ-(Ala)3nitroanilide (SANA) as the substrate, monitoring the release of $p$-nitroaniline by the method described [20] with a few modifications. The inhibitory activity determined the intensity of color released during cleavage of SANA by the action of elastase. Briefly, $1 \mathrm{mM}$ SANA was prepared in $0.1 \mathrm{M}$ Tris- $\mathrm{HCl}$ buffer ( $\mathrm{pH} 8.0)$ and this solution $(200 \mu \mathrm{l})$ was added to the stock sample solution $(20 \mu \mathrm{l})$. The solutions were vortexed and preincubated 
for $10 \mathrm{~min}$ at $25^{\circ} \mathrm{C}$ and then $20 \mu \mathrm{l}$ of elastase from porcine pancreas (0.03 units/ml) was added. After vortexing, each solution was placed in a water bath at $25{ }^{\circ} \mathrm{C}$ for $10 \mathrm{~min}$ and the absorbance was measured at $410 \mathrm{~nm}$. Controls were performed with water and methanol, while oleanolic acid as a positive control.

\section{Hyaluronidase inhibition assay}

Hyaluronidase inhibitory assay was performed by the method described previously [21] which depends on the fact that substance forms a precipitate with protein in an acidic solution. A test sample of $5 \mu$ l was pre-incubated with hyaluronidase from bovine test $(1.50$ units in $100 \mu \mathrm{l}$ ), sodium phosphate buffer $20 \mathrm{mM}$ (pH 7.0) with sodium chloride $77 \mathrm{mM}$ and bovine serum albumin (BSA) $0.01 \%$ for $10 \mathrm{~min}$ at $37^{\circ} \mathrm{C}$. Subsequently, the assay was initiated by adding hyaluronic acid sodium salt from rooter comb $100 \mu \mathrm{l}(0.03 \%$ in $300 \mathrm{mM}$ sodium phosphate, $\mathrm{pH} 5.35)$ to the incubation mixture and incubated further for $45 \mathrm{~min}$ at $37{ }^{\circ} \mathrm{C}$. Hyaluronic acid (undigested) was precipitated with acid albumin solution $(1 \mathrm{ml})$, made up of bovine serum albumin $0.1 \%$ in sodium acetate $24 \mathrm{mM}$ and acetic acid $79 \mathrm{mM}(\mathrm{pH} 3.75)$. It was allowed to stand at room temperature for $10 \mathrm{~min}$ and then the absorbance was measured at $600 \mathrm{~nm}$. Oleanolic acic was used as positive control and the sample solutions were used as controls.

The percentage inhibition for collagenase, elastase and hyaluronidase assays were calculated by:

Enzyme inhibition activity $(\%)=(1-\mathrm{B} / \mathrm{A}) \times 100$, where $A$ is the enzyme activity without sample and $B$ is the activity in presence of the sample.

\section{Tyrosinase inhibition assay}

Tyrosinase activity inhibition was determined by the method as described previously [22] by measuring the DOPA chrome formed due to the action of tyrosinase enzyme on tyrosine substrate. In brief, sample extracts were dissolved in corresponding solvent to make the different concentrations $(\mu \mathrm{g} / \mathrm{ml})$. The 96 -well plate was set up in the following order; $120 \mu \mathrm{l}$ of phosphate buffer (20 mM, pH 6.8), $20 \mu \mathrm{l}$ of sample and $20 \mu \mathrm{l}$ of mushroom tyrosinase (500 units/ml in $20 \mathrm{mM}$ phosphate buffer). After incubation at $25{ }^{\circ} \mathrm{C}$ for $15 \mathrm{~min}$, reaction was initiated by adding $20 \mu \mathrm{l}$ of $0.85 \mathrm{mM}$ L-tyrosine solution to each well. The enzyme activity was determined by measuring the absorbance at $470 \mathrm{~nm}$. Kojic acid was used as a positive control. The percentage of tyrosinase inhibition was calculated as follows:

Tyrosinase inhihition $(\%)=[(\mathrm{A}-\mathrm{B})-(\mathrm{C}-\mathrm{D})] /(\mathrm{A}-$ B) $x 100$, where $A$ is the absorbance of the control with the enzyme, $\mathrm{B}$ is the absorbance of the control without the enzyme, $\mathrm{C}$ is the absorbance of the test sample with the enzyme and D is the absorbance of the test sample without the enzyme.

\section{Statistical analysis}

The data were analyzed by one-way ANOVA using SPSS version 16.0 for Windows. Upon significant difference, means were separated using Tukey HSD range test at $p=0.01$ with three replications. In some cases, only means and standard deviation of the sample means are presented.

\section{Results}

The radical scavenging activities of aqueous extracts were found superior to ethanol extracts $(p=0.01)$. The seed and rhizome had better antioxidant activities. For DPPH assay, seed extracts showed the best activity $\left(\mathrm{IC}_{50}=10.33 \pm 0.03 \mu \mathrm{g} / \mathrm{ml}\right)$ followed by rhizome $\left(\mathrm{IC}_{50}=25.31 \pm 0.67 \mu \mathrm{g} / \mathrm{ml}\right)$. In case of ABTS radical scavenging activity, the $\mathrm{IC}_{50}$ values for rhizome and seed extracts were $73.94 \pm 1.23$ and $84.29 \pm 0.72 \mu \mathrm{g} / \mathrm{ml}$, respectively. The scavenging of superoxide radicals also showed both seed and rhizome extract to have better activities than other parts with $\mathrm{IC}_{50}$ of $58.55 \pm 0.31$ and $64.70 \pm 0.72 \mu \mathrm{g} / \mathrm{ml}$, respectively. However, rhizome and seed aqueous extracts had weaker inhibitory effect than positive control BHT on DPPH, ABTS and PMS-NADH radical scavenging assays $\left(\mathrm{IC}_{50}=11.74 \pm 1.23,14.26 \pm 0.16\right.$ and $24.80 \pm 0.98 \mu \mathrm{g} / \mathrm{ml})(p=0.01)$ [Table 1]. It was also found that the seed and rhizome aqueous extracts contained higher amounts of phenolic compounds

\section{Table 1 Radical scavenging activity of six parts of $\boldsymbol{A}$. zerumbet extracts on DPPH, ABTS and PMS-NADH superoxide}

\begin{tabular}{llccc}
\hline Sample & Extraction & \multicolumn{3}{c}{ Inhibitory effect $\left(\mathbf{I} \mathbf{C}_{50} ; \boldsymbol{\mu g} / \mathbf{m L}\right)$} \\
\cline { 3 - 5 } & & DPPH & ABTS & PMS-NADH \\
\hline BHT & & $11.74 \pm 0.15 \mathrm{a}^{\prime}$ & $14.26 \pm 0.16 \mathrm{a}$ & $24.80 \pm 0.98 \mathrm{a}$ \\
Rhizome & Aqueous & $25.31 \pm 0.67 \mathrm{~b}$ & $73.94 \pm 1.23 \mathrm{~b}$ & $64.70 \pm 0.72 \mathrm{c}$ \\
& Ethanol & $145.07 \pm 1.68 \mathrm{e}$ & $155.86 \pm 4.09 \mathrm{f}$ & $113.37 \pm 1.24 \mathrm{~d}$ \\
Stem & Aqueous & $144.03 \pm 0.27 \mathrm{e}$ & $127.97 \pm 1.70 \mathrm{~d}$ & $215.09 \pm 0.28 \mathrm{~h}$ \\
& Ethanol & $293.08 \pm 0.17 \mathrm{~g}$ & $223.17 \pm 0.26 \mathrm{i}$ & $132.27 \pm 1.33 \mathrm{e}$ \\
Leaf & Aqueous & $165.60 \pm 0.44 \mathrm{f}$ & $143.77 \pm 1.37 \mathrm{e}$ & $191.24 \pm 0.20 \mathrm{~g}$ \\
& Ethanol & $586.47 \pm 0.77 \mathrm{j}$ & $206.65 \pm 0.85 \mathrm{~h}$ & $168.23 \pm 4.77 \mathrm{f}$ \\
Flower & Aqueous & $132.19 \pm 1.02 \mathrm{C}$ & $140.50 \pm 1.18 \mathrm{e}$ & $117.32 \pm 1.46 \mathrm{~d}$ \\
& Ethanol & $559.01 \pm 3.61 \mathrm{~h}$ & $293.90 \pm 3.64 \mathrm{k}$ & $210.50 \pm 4.03 \mathrm{~h}$ \\
\multirow{2}{*}{ Pericarp } & Aqueous & $140.91 \pm 0.30 \mathrm{de}$ & $163.41 \pm 1.07 \mathrm{~g}$ & $169.02 \pm 1.01 \mathrm{f}$ \\
& Ethanol & $580.38 \pm 0.26 \mathrm{i}$ & $246.71 \pm 0.85 \mathrm{j}$ & $166.11 \pm 0.52 \mathrm{f}$ \\
Seed & Aqueous & $10.33 \pm 0.03 \mathrm{a}$ & $84.29 \pm 0.72 \mathrm{C}$ & $58.55 \pm 0.31 \mathrm{~b}$ \\
& Ethanol & $136.63 \pm 0.33 \mathrm{~cd}$ & $137.92 \pm 1.74 \mathrm{e}$ & $56.12 \pm 1.08 \mathrm{~b}$ \\
\hline
\end{tabular}

${ }^{1}$ The data represent the means \pm SD of three determinations. Values with the same letter are not significantly different $(p=0.01)$ from each other. 
Table 2 Total phenolic content from six parts of $A$. zerumbet extracts

\begin{tabular}{lcc}
\hline Sample & \multicolumn{2}{c}{ Total phenolic content (GAE mg/g extract) } \\
\cline { 2 - 3 } & Aqueous extract & Ethanol extract \\
\hline Rhizome & $124.51 \pm 0.57 \mathrm{~b}^{\prime}$ & $38.50 \pm 0.47 \mathrm{~h}$ \\
Stem & $59.41 \pm 0.87 \mathrm{~d}$ & $9.60 \pm 0.04 \mathrm{j}$ \\
Leaf & $47.80 \pm 0.73 \mathrm{f}$ & $42.14 \pm 0.22 \mathrm{~g}$ \\
Flower & $75.15 \pm 0.23 \mathrm{C}$ & $12.90 \pm 0.11 \mathrm{i}$ \\
Pericarp & $58.42 \pm 0.18 \mathrm{~d}$ & $10.26 \pm 0.04 \mathrm{j}$ \\
Seed & $187.75 \pm 0.97 \mathrm{a}$ & $56.31 \pm 0.09 \mathrm{e}$
\end{tabular}

${ }^{1}$ The data represent the means \pm SD of three determinations. Values with the same letter are not significantly different $(p=0.01)$ from each other.

$(187.75 \pm 0.97$ and $124.51 \pm 0.57 \mathrm{GAE} \mathrm{mg} / \mathrm{g}$ extract, respectively) [Table 2].

The effect of six different structures of $A$. zerumbet on elastase, hyaluronidase and tyrosinase inhibitions showed that rhizome had stronger inhibitory activity than the other parts $\left(\mathrm{IC}_{50}=57.43 \pm 0.18,35.02 \pm 0.75\right.$ and $21.84 \pm 0.77 \mu \mathrm{g} / \mathrm{ml}$, respectively). Pericarp showed higher inhibitory activities against collagenase $\left(\mathrm{IC}_{50}=45.67 \pm 0.50 \mu \mathrm{g} / \mathrm{ml}\right)$. However, test samples had weaker inhibition than positive control, oleanolic acid $\left(\mathrm{IC}_{50}=17.95 \pm 0.23,10.91 \pm 0.03\right.$ and $5.28 \pm 0.19 \mu \mathrm{g} / \mathrm{ml}$, respectively) on collagenase, elastase, hyaluronidase activities and lower ihhibitory effect than kojic acid $\left(\mathrm{IC}_{50}=8.90 \pm 0.22 \mu \mathrm{g} / \mathrm{ml}\right)$ on tyrosinase acitivity $(p=0.01)$ [Figure 2].
The amount of DK, DDK and labdadiene in the crude extracts of six different structures from $A$. zerumbet with aqueous and ethanol solvents extraction are presented in Table 3. DK and DDK were found in all structures of plant and in both solvent extractions. The rhizome aqueous extract contained higher amount of DK $(1.23 \mathrm{mg} / \mathrm{g}$ crude extract) followed by pericarp aqueous extract and rhizome ethanol extract (1.15 and $1.14 \mathrm{mg} / \mathrm{g}$ crude extract, respectively). DDK was found in high amount in pericarp aqueous extract $(0.85 \mathrm{mg} / \mathrm{g}$ crude extract) followed by rhizome aqueous extract $(0.62 \mathrm{mg} / \mathrm{g}$ crude extract). Labdadiene was present in higher amount in seed ethanol and aqueous extracts $(1.00$ and $0.96 \mathrm{mg} / \mathrm{g}$ crude extract, respectively) followed by rhizome and pericarp aqueous extracts $(0.81$ and $0.75 \mathrm{mg} / \mathrm{g}$ crude extract), moreover, the crude extracts of stem, leaf and flower did not contain labdadiene.

The inhibitory properties of isolated compounds on antioxidant are shown in Figure 3. DK showed the highest inhibitory properties on DPPH, ABTS and PMS$\mathrm{NADH}$ radical scavenging assays $\left(\mathrm{IC}_{50}=122.14 \pm 1.40\right.$, $110.08 \pm 3.34$ and $127.78 \pm 4.75 \mu \mathrm{g} / \mathrm{ml}$, respectively). On statistical analysis of the result, isolated compounds were weaker inhibitors on antioxidant than BHT $(p=0.01)$.

Among the isolated compounds, DK showed stronger inhibitory activities against collagenase, elastase, hyaluronidase and tyrosinase $\left(\mathrm{IC}_{50}=24.93 \pm 0.97,19.41 \pm 0.61\right.$, $19.48 \pm 0.24$ and $76.67 \pm 0.50 \mu \mathrm{g} / \mathrm{ml}$, respectively) than

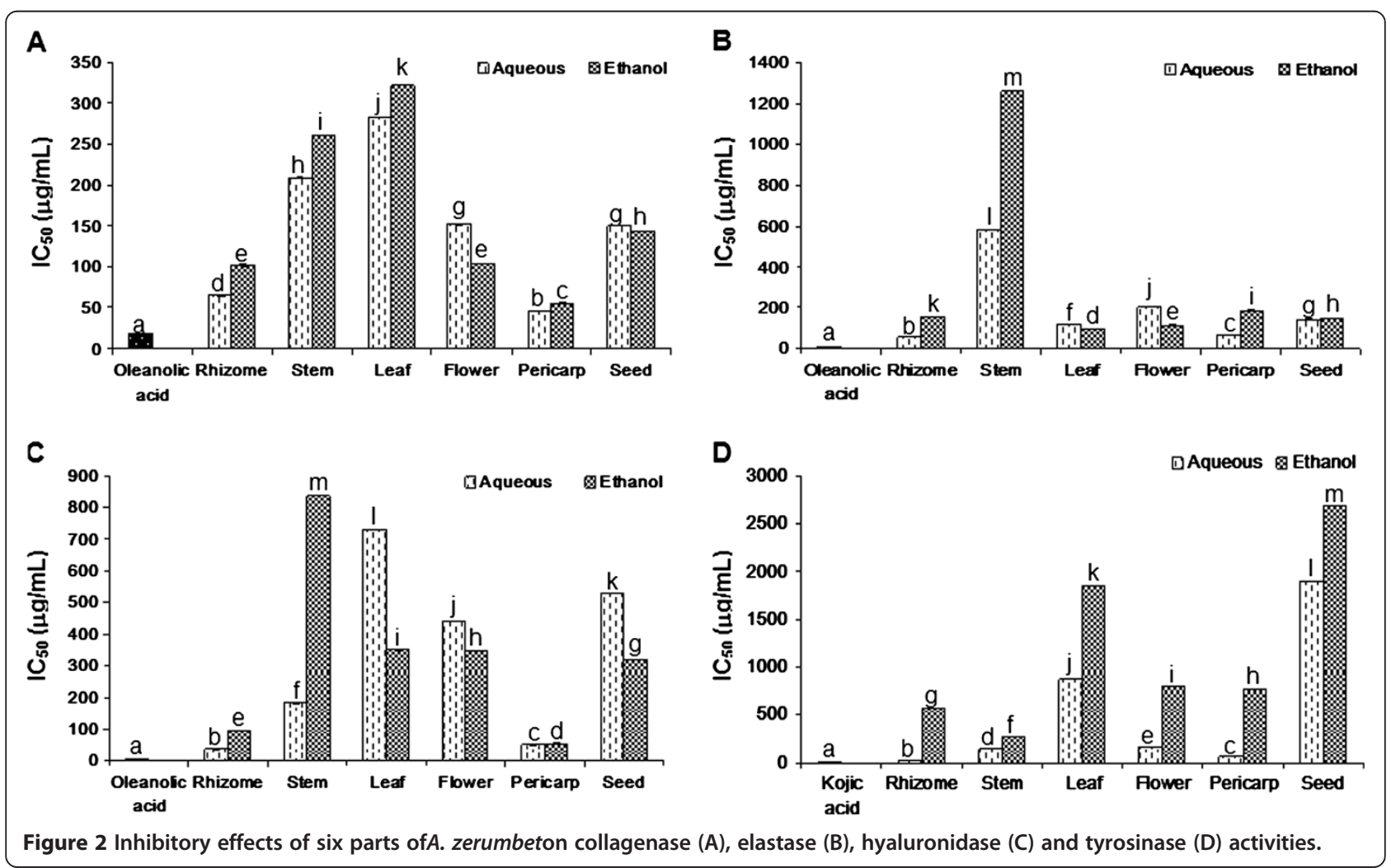


Table 3 Amount of DK, DDK and labdadiene in aqueous and ethanol extracts from six different structures of $A$. zerumbet

\begin{tabular}{lllll}
\hline Sample & Extraction & \multicolumn{3}{c}{ Amount of compound (mg/ g crude extracts) } \\
\cline { 2 - 5 } & & DK & DDK & Labdadiene \\
\hline Rhizome Aqueous & $1.23 \pm 0.03 \mathrm{a}$ & $0.62 \pm 0.02 \mathrm{~b}$ & $0.81 \pm 0.03 \mathrm{~b}$ \\
Stem & Ethanol & $1.14 \pm 0.01 \mathrm{~b}$ & $0.08 \pm 0.01 \mathrm{fg}$ & $0.00 \pm 0.00 \mathrm{c}$ \\
& Aqueous & $0.79 \pm 0.03 \mathrm{de}$ & $0.30 \pm 0.01 \mathrm{~d}$ & $0.00 \pm 0.00 \mathrm{c}$ \\
Leaf & Aqueous & $0.86 \pm 0.02 \mathrm{~d}$ & $0.46 \pm 0.02 \mathrm{c}$ & $0.00 \pm 0.00 \mathrm{c}$ \\
& Ethanol & $0.80 \pm 0.01 \mathrm{de}$ & $0.07 \pm 0.02 \mathrm{fg}$ & $0.00 \pm 0.00 \mathrm{c}$ \\
Flower & Aqueous & $0.12 \pm 0.02 \mathrm{f}$ & $0.11 \pm 0.01 \mathrm{f}$ & $0.00 \pm 0.00 \mathrm{c}$ \\
& Ethanol & $0.83 \pm 0.02 \mathrm{de}$ & $0.06 \pm 0.01 \mathrm{fg}$ & $0.00 \pm 0.00 \mathrm{c}$ \\
Pericarp & Aqueous & $1.15 \pm 0.03 \mathrm{~b}$ & $0.85 \pm 0.03 \mathrm{a}$ & $0.75 \pm 0.04 \mathrm{~b}$ \\
& Ethanol & $0.79 \pm 0.03 \mathrm{de}$ & $0.11 \pm 0.01 \mathrm{f}$ & $0.00 \pm 0.00 \mathrm{c}$ \\
Seed & Aqueous & $0.94 \pm 0.02 \mathrm{c}$ & $0.05 \pm 0.01 \mathrm{~g}$ & $0.96 \pm 0.01 \mathrm{a}$ \\
& Ethanol & $0.78 \pm 0.02 \mathrm{e}$ & $0.06 \pm 0.02 \mathrm{fg}$ & $1.00 \pm 0.09 \mathrm{a}$ \\
\hline
\end{tabular}

${ }^{1}$ The data represent the means \pm SD of three determinations. Values with the same letter in one column are not significantly different $(p=0.01)$ from each other.

DDK and labdadiene. However, isolated compounds had lower inhibitory effect than oleanolic acid [Figure 4] $(p=0.01)$.

\section{Discussion}

Free radicals, such as ROS, are known to cause damage to cells during the process of aging thereby leading to a wide range of degenerative diseases [23]. Furthermore, the interactions between human body and the environment make the skin chronically exposed to both endogenous and environmental pro-oxidant agents which aid to the generation of ROS [24]. One of the important functions of skin is to protect from harmful environments. However, due to unusual disruption of connective tissues, the formation of free radicals, and the ultraviolet radiation result in skin wrinkling and pigmentation [25]. Several studies have explored on the prevention of these the skin abnormalities using plant extracts and phenolic compounds contribute in curing of skin diseases. Plant extracts such as pomegranate [26], tea [27] and wine [28] extracts have been shown to reduce the oxidative damage of UV light in skin. Purified phenolic compounds such as anthocyanins [29], proanthocyanidin [30] and EGCG [31] were found to inhibit the UV-radiation-induced oxidative stress and cell damage in human keratinocytes.

In this study, we screened the inhibitory activities of extracts obtained from six different structures of $A$. zerumbet with aqueous and ethanol extracts for ranking the efficacies. The results of preliminary screening showed that the rhizome and seed aqueous extracts had high

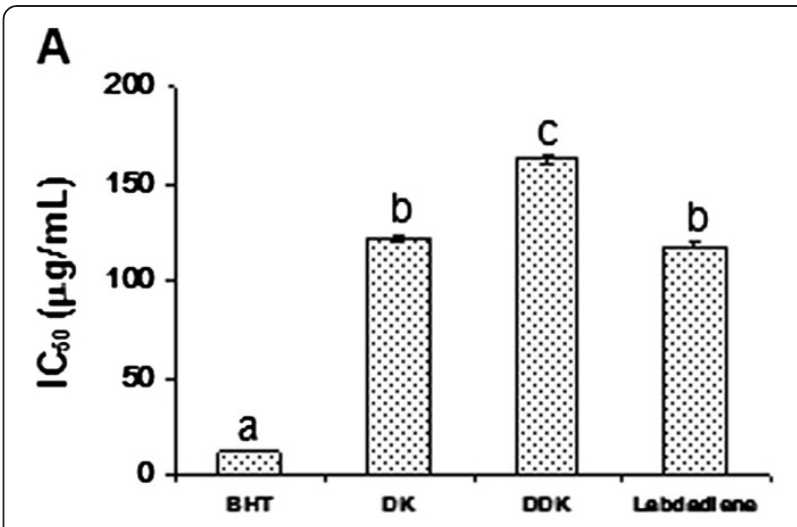

B

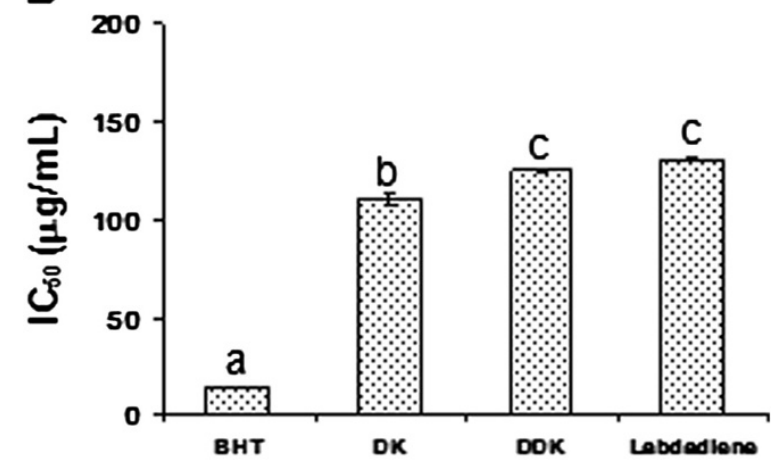

C

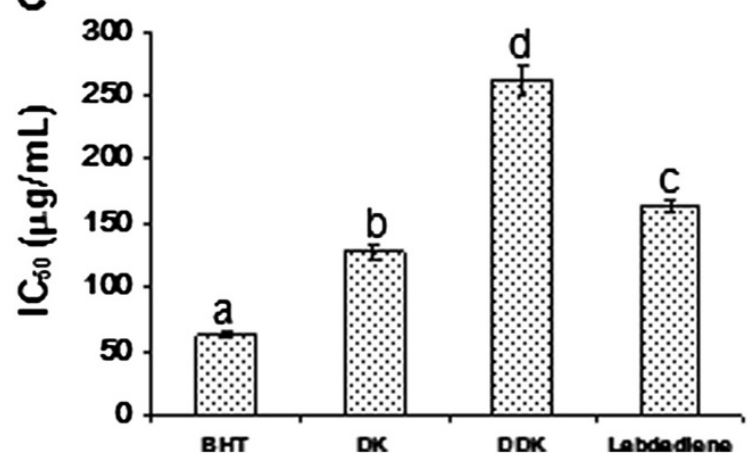

Figure 3 Effects of DK, DDK and labdadiene on DPPH (A), ABTS (B) and PMS-NADH (C) radical scavenging inhibitions.

antioxidant. Likewise, we found that the seed and rhizome aqueous extracts contained higher amounts of total phenolic contents, which may be the reasons for stronger radical scavenging activities. For skin diseases-related enzymes assays, rhizome aqueous extract exhibited the strongest activities in three of the performed assays while pericarp aqueous extract had better result in the collagenase inhibition. We quantified the amount of DK, DDK and labdadiene in all of test samples. The rhizome aqueous extract contained high amount of three compounds that may be the reason for stronger inhibitory properties. The inhibitory properties of these compounds have been 

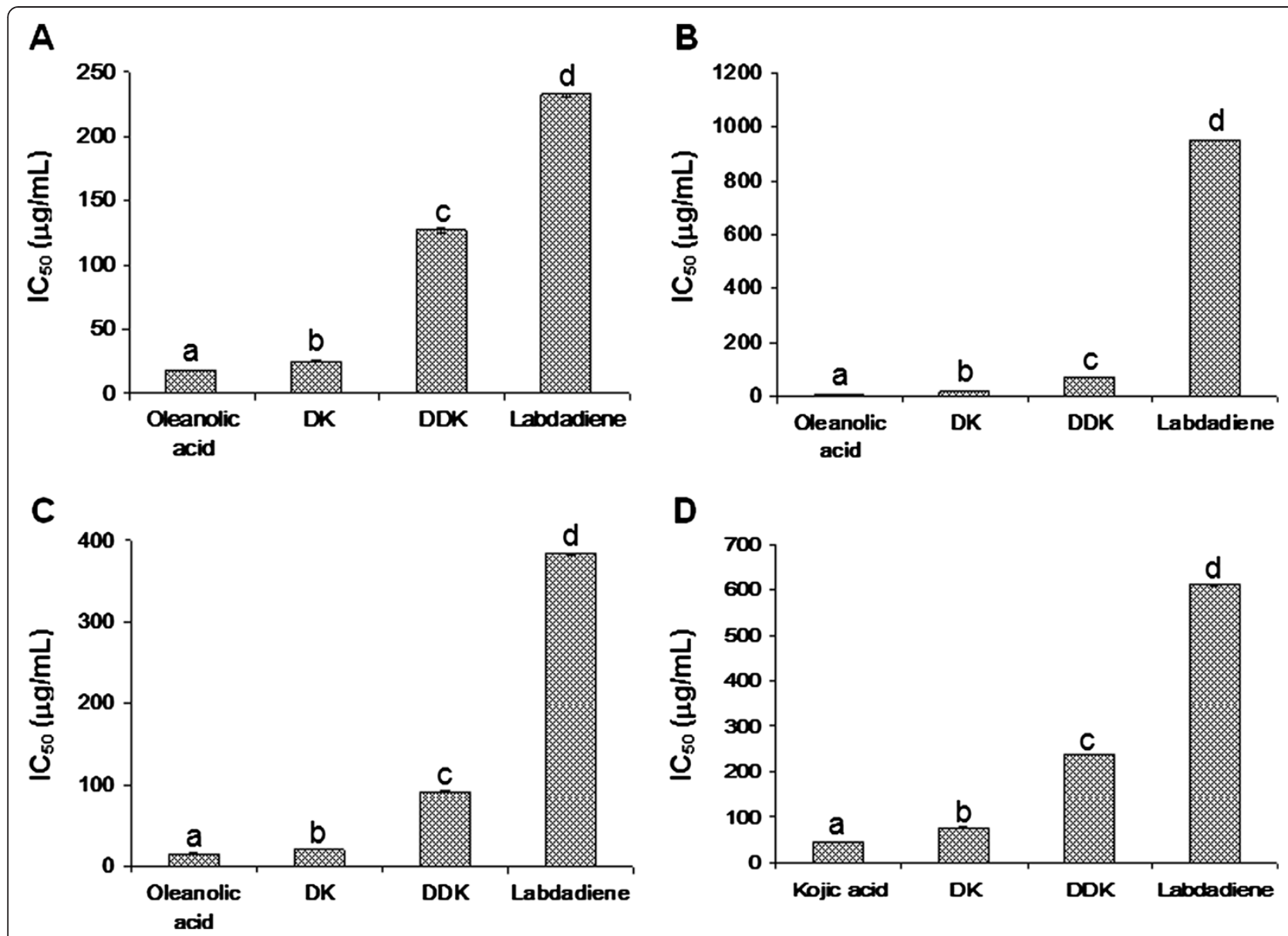

Figure 4 Inhibitory effects of DK, DDK and labdadiene on collagenase (A), elastase (B), hyaluronidase (C) and tyrosinase (D) activities.

published. For instance, DK had inhibitory effect on human platelet aggregation [32]. Beside, Upadhyay et al. [12] presented that DK strongly inhibited HIV-1 integrase and neuraminidase activities. Furthermore, Chompoo et al. [13] reported that labdadiene had strong reduction of advanced glycation end products formation. We further continued to study the potency of three isolated compounds isolated from the rhizomes on antioxidant and skin diseases-related enzymes activities.

Among the isolated compounds, DK exhibited the strongest activity in all of antioxidant assays. DK and DDK are the pyrone compounds, interestingly these compounds differ with one another by a single $\pi$-bond at C7-C8. DK contains a double bond and it seems that the presence of double bond has significant impact on antioxidant. Singlet oxygen reacts directly with the double bond of the unsaturated fatty acid by a concerted addition, the so-called "ene" reaction. This is a concerted reaction between singlet oxygen and carbon-carbon double bond in which the oxygen molecule is inserted at either carbon atom of the $\mathrm{C}=\mathrm{C}$ bond [33,34]. Heim et al. [35] have found that flavonoids with a double bond are the better antioxidant. The double bond in the heterocycle or polymerization of the nuclear structure increases activity by affording a more stable flavonoid radical through conjugation and electron delocation. Moreover, Stahl et al. [36] reported that due to conjugated double bond in the polyene backbone of carotenoid structure, a major role in the protection of plants against photooxidative processes, which determines their light absorbing properties and influences the antioxidant activity. They are also part of the antioxidant defense system in animals and humans.

The skin diseases-related enzyme assays revealed that DK also has strong activity in among of isolated compounds. Several previous studies have been reported the ability of pyrone to exhibit skin diseases-related enzymes. Hosoe et al. [37] reported that $\gamma$-pyrone derivative, lepidepyrone, was a major hyaluronidase inhibitory compound. Cook et al. [38] presented that 3-(1-oxoalkyl)-4-hydroxy6-alkyl-2-pyrone was found to be most effective to inhibit human sputum elastase. Huang et al. [39] demonstrated that dimeric naphtha- $\gamma$-pyrone, rubrofusarin, exhibited moderate tyrosinase activity, in addition, 6- $n$-pentyl- $\alpha$ - 
pyrone have been recorded as a potent tyrosinase inhibitor [40]. Moreover, pyrone have been presented to restrain other diseases. Hong [41] reported that tricyclic analogs and tricyclic pyrone compounds directly bind to and inhibit formation of amyloid- $\beta$ (A $\beta$ ) aggregates in cell model representing Alzheimer's disease. Yan et al. [42] mentioned that 3-hydroxy-4-pyrones and 5-amino-3-hydroxy4-pyrone derivatives have been evaluated as inhibitor of matrix metalloproteinases. Hence we assume that DK is a pyrone compound and contain carbon double bond which may have a substantial role in inhibiting the skin diseasesrelated enzymes.

\section{Conclusion}

This study revealed that the rhizome aqueous extract of A. zerumbet had indicated strong antioxidant and skin diseases-related enzymes. Since isolated compounds from rhizome of $A$. zerumbet, DK, was identified as a moderated potent inhibitor of antioxidant. Also, it was indicated that there was strong inhibition of skin diseases-related enzymes. Our results showed that DK have probable applications in preventing the skin against photo-oxidation. However further researches are necessary to use it as a lead compounds in drug designing.

\section{Abbreviations \\ DPPH: 1,1-Diphenyl-2-picrylhydrazyl; BHT: tert-butyl hydroxytoluene kojic acid, gallic acid; ABTS: 2,2-azino-bis(3-ethylbenzothiazoline-6-sulfonic acid); NBT: Diammonium salt nitro blue tetrazolium; PMS: Phenazine methosulfate; BSA: Bovine serum albumin; NADH: Nicotinamide adenine dinucleotide- reduced; SANA: N-succ-(Ala)3-nitroanilide; FALGPA: N-[3-(2-furyl)acryloyl]-Leu- Gly-Pro-Ala.}

\section{Competing interest}

The authors declare that they have no competing interests.

\begin{abstract}
Authors' contributions
J was responsible for the conception and design, carried out all experiments, performed data analysis and drafted the manuscript. A was responsible for the conception and drafted the manuscript. F participated in the laboratory investigation and drafted the manuscript. S made substantial contribution to conception and revised it critically for important intellectual content and corresponding author. All authors read and approved the final manuscript.
\end{abstract}

\section{Acknowledgement}

We express sincere thanks to Ms. Carol J. Ashman (the native-English speaker) at Lexington Circle Wildwood, Florida for English editing.

\section{Author details \\ ${ }^{1}$ Department of Bioscience and Biotechnology, The United Graduate School of Agricultural Science, Kagoshima University, 1-21-24 Korimoto, Kagoshima 890-0065, Japan. ²Department of Bioscience and Biotechnology, Faculty of Agriculture, University of the Ryukyus, Senbaru 1, Nishihara-cho, Okinawa 903-0213, Japan}

Received: 1 November 2011 Accepted: 24 July 2012

Published: 24 July 2012

\section{References}

1. Ndiaye M, Philippe C, Mukhtar H, Ahmad N: The grape antioxidant resveratrol for skin disorders: promise, prospects, and challenges. Arch Biochem Biophys/ 2011, 508:164-170.
2. Svobodová A, Psotová J, Walterová D: Natural phenolics in the prevention of UV-induced skin damage. A review. Biomed Papers 2003, 147:137-145.

3. Bickers DR, Athar M: Oxidative stress in the pathogenesis of skin disease. J Invest Dermatol 2006, 126:2565-2575.

4. Niederländer HAG, van Beek TA, Bartasiute A, Koleva II: Antioxidant activity assays on-line with liquid chromatography. J Chromatogr A 2008, 1210:121-134.

5. Thring TSA, Hili P, Naughton DP: Anti-collagenase, anti-elastase and antioxidant activities of extracts from 21 plants. BMC complement Altern Med 2009, 9:27.

6. Lee KK, Kim JH: Inhibitory effects of 150 plant extracts on elastase activity, and their anti-inflammatory effects. Int J Cosmet Sci 1999, 21:71-82.

7. Barla F, Higashijima H, Funai S, Sugimoto K, Harada N, Yamaji R, Fujita T, Nakano $Y$, Inui $\mathrm{H}$ : Inhibitive effects of alkyl gallates on hyaluronidase and collagenase. Biosci Biotechnol Biochem 2009, 73:2335-2337.

8. Tief K, Hahne M, Schmidt A, Beermann F: Tyrosinase, the key enzyme in melanin systhesis, is expressed in murine brain. Eur J Biochem 1996, 241:12-16.

9. Murakami S, Li W, Matsuura M, Satou T, Hayashi S, Koike K: Composition and seasonal variation of essential oil inAlpinia zerumbetfrom Okinawa Island. J Nat Med 2009, 63:204-208.

10. De Araújo Pinho FVS, Coelho-de-Souza AN, Morais SM, Santos CF, LealCardoso $\mathrm{JH}$ : Antinociceptive effect of the essential oil ofAlpinia zerumbeton mice. Phytomedicine 2005, 12:482-486.

11. De Moura RS, Emiliano AF, de Carvalho LCRM, Souza MAV, Guedes DC, Tano T, Resende AC: Antihypertensive and endothelium-dependent vasodilator effects ofAlpinia zerumbet, a medicinal plant. J Cariovasc Pharmacol 2005, 46:288-294.

12. Elzaawely AA, Xuan TD, Tawata S: Essential oil, kava pyrones and phenolic compounds from leaves and rhizomes ofAlpinia zerumbet(Pers.) B.L. Burtt. \& R.M. Sm. And their antioxidant activity. Food Chem 2007, 103:486-494.

13. Upadhyay A, Chompoo J, Kishimoto W, Makise T, Tawata S: HIV-1 integrase and neuraminidase inhibitors fromAlpinia zerumbet. J Agric Food Chem 2011, 59:2857-2862.

14. Chompoo J, Upadhyay A, Kishimoto W, Makise T, Tawata S: Advanced glycation end products inhibitors fromAlpinia zerumbetrhizomes. Food Chem 2011, 129:709-715.

15. Boskou G, Salta FN, Chrysostomou S, Mylona A, Chiou A, Andrikopoulos NK: Antioxidant capacity and phenolic profile of table olives from the Greek market. Food Chem 2006, 94:558-564.

16. Hsu CF, Peng H, Basle C, Travas-Sejdic J, Kilmartin PA: ABTS.+ scavenging activity of polypyrrole, polyaniline and poly $(3,4-$ ethylenedioxythiophene). Polym Int 2011, 60:69-77.

17. Lau KM, He ZD, Dong H, Fung KP, But PPH: Anti-oxidative, antiinflammatory and hepato-protective effects of Ligustrum robustum. J Ethnopharmacol 2002, 83:63-71.

18. Djeridane A, Youffi M, Nadjemi B, Boutassouna D, Stocker P, Vidal N: Antioxidant activity of some algerian medicinal plants extracts containing phenolic compounds. Food Chem 2006, 97:654-660.

19. Van Wart HE, Steinbrink DR: A continuous spectrophotometric assay forClostridium histolyticumcollagenase. Analyt Biochem 1981, 113:356-365.

20. Kraunsoe JAE, Claridge TDW, Lowe G: Inhibition of human leukocyte and porcine pancreatic elastase by homologues of bovine pancreatic trypsin inhibitor. Biochemistry 1996, 35:9090-9096.

21. Kim JH, Byun JC, Bandi AKR, Hyun CG, Lee NH: Compounds with elastase inhibition and free radical scavenging activities fromCallistemon lanceolatus. J Med Plant Res 2009, 3:914-920.

22. Tadtong S, Viriyaroj A, Vorarat S, Nimkultat S, Suksamrarn S: Antityrosinase and antibacterial activities of mangosteen pericarp extract. $J$ Health Res 2009, 23:99-102.

23. Duan XJ, Zhang WW, Li XM, Wang BG: Evaluation of antioxidant property of extract and fractions obtained from a red alga, Polysiphonia urceolata. Food Chem 2006, 95:37-43.

24. Briganti S, Picardo M: Antioxidant activity, lipid peroxidation and skin disease. What's new. J Eur Acad Dermatol Venereol 2003, 17:663-669.

25. Kim HH, Lee MJ, Lee SR, Kim KH, Cho KH, Eun HC, Chung JH: Augmentation of UV-induced skin wrinkling by infrared irradiation in hairless mice. Mech Ageing Dev 2005, 126:1170-1177. 
26. Afaq F, Zaid MA, Khan N, Dreher M, Mukhtar H: Protective effect of pomegranate-derived products on UVB-mediated damage in human reconstituted skin. Exp Dermatol 2009, 18:553-561.

27. Wang ZY, Huang MT, Lou YR, Xie JG, Reuhl KR, Newmark HL, Ho CT, Yang CS, Conney AH: Inhibitory effect of black tea, green tea, decaffeinated black tea, and decaffeinated green tea on Ultraviolet B Light-induced skin carcinogenesis in 7,12-dimethylbenz[a]anthracene-initiated. Cancer Res 1994, 54:3428-3435.

28. Matito C, Agell N, Sanchez-Tena S, Torres JL, Cascante M: Protective effect of structurally diverse grape procyanidin fractions against UV-induced cell damage and death. J Agric Food Chem 2011, 59:4489-4495.

29. Tsoyi K, Park HB, Kim YM, Chung Jl, Shin SC, Shim HJ, Lee WS, Seo HG, Lee $\mathrm{JH}$, Chang KC, Kim HJ: Protective effect of anthocyanins from black soybean seed coats on UVB-induced apoptotic cell death in vitro and in vivo. J Agric Food Chem 2008, 56:10600-10605.

30. Mantena SK, Katiyar SK: Grape seed proanthocyanidins inhibit UV-radiation-induced oxidative stress and activation of MAPK and NK-KB signaling in human epidermal keratinocytes. Free Radical Biol Med 2006, 40:1603-1614.

31. Tobi SE, Gilbert M, Paul N, McMillan TJ: The green tea polyphenol, epigallocatechin-3-gallate, protects against the oxidative cellular and genotoxic damage of UVA radiation. Int I Cancer 2002, 102:439-444.

32. Jantan I, Raweh SM, Sirat HM, Jamil S, Yasin YHM, Jali J, Jamal JA: Inhibitory effect of compounds from Zingiberaceae species on human platelet aggregation. Phytomedicine 2008, 15:306-309.

33. Chan HWS: Photo-sensitized oxidation of unsaturated fatty acid methyl esters. The identification of different pathways. JAOCS 1977, 54:100-104.

34. Terao J, Matsushita S: The isomeric compositions of hydroperoxides produced by oxidation of arachidonic acid with singlet oxygen. Agric Biol Chem 1981, 45:587-593.

35. Heim KE, Tagliaferro AR, Bobilya DJ: Flavonoid antioxidants: chemistry, metabolism and structure-activity relationships. J Nutr Biochem 2002, 13:572-584.

36. Stahl W, Sies H: Antioxidant activity of carotenoids. Mol Aspects Med 2003, 24:345-351.

37. Hosoe T, Sakai H, Ichikawa M, Itabashi T, Ishizaki T, Kawai K: Lepidepyrone, a new $\gamma$-pyrone derivative, fromNeolentinus lepideus, inhibits hyaluronidase. J Antibiot 2007, 60:388-390.

38. Cook L, Ternai B, Ghosh P: Inhibition of human sputum elastase by substituted 2-pyrone. J Med Chem 1987, 30:1017-1023.

39. Huang HB, Feng XJ, Liu L, Chen B, Lu YJ, Ma L, She ZG, Lin YC: Three dimeric naptho- $\gamma$-pyrones from the mangrove endophytic fungusAspergillus tubingensisisolated fromPongamia pinnata. Planta Med 2010, 76:1888-1891.

40. Li X, Kim MK, Lee U, Kim SK, Kang JS, Choi HD, Son BW: Myrothenones $A$ and $B$, cyclopentenone derivatives with tyrosinase inhibitory activity from the marine-direved fungusMyrothecium sp. Chem Pharm Bull 2005, 53:453-455.

41. Hong HS, Rana S, Barrign L, Shi A, Zhang Y, Zhou F, Jin LW, Hua DH: Inhibition of Alzheimer's amyloid toxicity with a tricyclic pyrone molecule in vitro and in vivo. J Neurochem 2009, 108:1097-1108.

42. Yan YL, Cohen SM: An efficient synthesis of 5-amido-3-hydroxy-4-pyrones as inhibitors of matrix metalloproteinases. Org Lett 2007, 9:2517-2520.

doi:10.1186/1472-6882-12-106

Cite this article as: Chompoo et al:: Effect of Alpinia zerumbet components on antioxidant and skin diseases-related enzymes. $B M C$ Complementary and Alternative Medicine 2012 12:106.

\section{Submit your next manuscript to BioMed Central and take full advantage of:}

- Convenient online submission

- Thorough peer review

- No space constraints or color figure charges

- Immediate publication on acceptance

- Inclusion in PubMed, CAS, Scopus and Google Scholar

- Research which is freely available for redistribution

Submit your manuscript at www.biomedcentral.com/submit
Ciomed Central 